\title{
Clinical characteristics, late effects and outcomes in pineoblastomas in children: a single center experience
}

\author{
Ömer Görgün ${ }^{1, *}$, Başak Koç ${ }^{1, *}$, Rejin Kebudi ${ }^{1 \oplus}$, Johannes E Wolff2 ${ }^{2}$, \\ Abut Kebudi $^{3 \oplus}$, Emin Darendeliler ${ }^{4 \oplus}$ \\ ${ }^{1}$ Division of Pediatric Hematology-Oncology and ${ }^{4}$ Department of Radiation Oncology, İstanbul University Oncology Institute, \\ İstanbul, Turkey; ${ }^{2}$ Division of Pediatric Hematology- Oncology, MD Anderson Cancer Center, Houston, TX, USA; ${ }^{3}$ Division of \\ Surgical Oncology, Okan University Medical Faculty, İstanbul, Turkey.
}

\begin{abstract}
Background. Pineoblastomas (PB) are rare tumors of the central nervous system and are more common in children. There is no consensus about standard of care. The objective of this study is to analyze the outcome of children with PB.
\end{abstract}

Methods. Six patients with PB who were diagnosed between 1990-2012 were evaluated retrospectively. Demographics, age of diagnosis, first complaint, tumor region, diagnosis type, seeding metastasis to the spinal axis or cerebrospinal fluid (CSF), treatment and survival of these patients were recorded.

Results. Three patients had subtotal resection and all patients received chemotherapy and craniospinal irradiation (CSI) after diagnosis. Median follow-up after treatment was 5.5 (range:1-19) years. Two patients are alive with no evidence of disease for 7.5 and 10 years, one of whom was diagnosed with papillary thyroid carcinoma 9.5 years after treatment. One of the patients who died had lived for 19 years after diagnosis.

Conclusions. Pineoblastomas are rare but very aggressive tumors; more effective treatment strategies are needed. Survivors should be followed up for late effects such as second malignancies and endocrine deficiencies.

Key words: pineoblastoma, children, late effects.

Pineoblastoma $(\mathrm{PB})$ is a rare embryonal tumor of the pineal gland. ${ }^{1}$ Histologically, $\mathrm{PB}$ are classified as WHO grade IV tumors. ${ }^{2,3}$ While they typically appear radiographically as focal enhancing mass, PB can also be locally invasive and spread outside the pineal region through the subarachnoid space. ${ }^{4}$ In this study, we assessed the demographics, treatment, late effects and outcome of PB patients who were diagnosed and treated in the Istanbul University Oncology Institute (IUOI) during 1990-2012.

\section{Rejin Kebudi}

rejinkebudi@yahoo.com

Received 6th April 2021, revised 30th May 2021, 30th June 2021, accepted 8th August 2021.

*Both authors have contributed equally

\section{Material and Methods}

During 1990-2012, 516 children with brain tumors were diagnosed and treated in the IUOI. Among these patients six (1.16 \%) were diagnosed with PB. Demographics, age of diagnosis, first complaint, tumor region, diagnosis type, seeding metastasis to the spinal axis or cerebrospinal fluid (CSF), treatment and survival of these patients were evaluated retrospectively from patient records. All patients had cranial and spinal axis MRI with contrast at diagnosis and during follow-up. Ethics Committee Approval: Istanbul University Cerrahpasa Medical Faculty Clinical Research Ethical Committee (12.02.2013/ 830458093507), Istanbul University Oncology Institute Academic Coordination Council (2013-206). 


\section{Results}

There were six patients diagnosed with PB between 1990 and 2012. Three of them were female, the median age of diagnosis was 5.75 years (2-14). The demographics of the patients are shown in Table I and modality of treatment, and outcomes are shown in Table II.

All patients had cranial magnetic resonance imaging (MRI) with contrast at diagnosis. Staging included spinal axis MRI with contrast for all patients, and CSF cytology, for all but patient \#2 (Table I) in whom lumbar puncture was contraindicated due to increased intracranial pressure. For pathologic diagnosis, three underwent only stereotactic biopsy because the tumor was considered unresectable by the neurosurgeons and three of them underwent subtotal resection of the tumor. In all patients, surgery was followed by craniospinal radiotherapy (CSRT) (except the 2-year-old patient) and chemotherapy.

All patients received CSRT after surgical biopsy or resection. One patient (Table I, pt \#1) received eight courses of chemotherapy before radiotherapy (RT) due to her young age $(<3$ years old). The disease progressed and RT was initiated, however she died in the intensive care unit without completing RT. Two of our patients (\#3 and \#4) were re-irradiated after the first RT due to relapse.

As chemotherapy, the patients received the institutional protocols used for embryonal brain tumors in the respective years of diagnosis. The first four patients received 8 courses of vincristine $\left(1.5 \mathrm{mg} / \mathrm{m}^{2}, 1\right.$ st day), etoposide (100 $\mathrm{mg} / \mathrm{m}^{2} /$ day $\mathrm{x} 3$ days) and cyclophosphamide (1gr/ $/ \mathrm{m}^{2} /$ day) (Table I, pt \#1-3) or carboplatin (560 mg/m²/day) (Table I, pt \#4).

One patient (Table I, pt \#5) received 8 courses of chemotherapy consisting of vincristine $\left(1.5 \mathrm{mg} / \mathrm{m}^{2}\right)$, cyclophosphamide $\left(1 \mathrm{gr} / \mathrm{m}^{2} /\right.$ day), procarbazine $\left(50 \mathrm{mg} / \mathrm{m}^{2}\right)$ and CCNU $(100 \mathrm{mg} /$ $\mathrm{m}^{2}$ ), all given in one day. She was given growth hormone 3 years after the end of chemotherapy for one year. While the PB remained controlled ever since, her medical history was not unremarkable: She developed papillary thyroid

Table I. Characteristics of patients.

\begin{tabular}{lllllll}
\hline $\begin{array}{l}\text { Patient } \\
\text { No (\#) }\end{array}$ & Gender & $\begin{array}{l}\text { Age } \\
\text { (years) }\end{array}$ & Complaint & $\begin{array}{l}\text { Primary Tumor } \\
\text { Region }\end{array}$ & Spinal axis & CSF \\
\hline 1 & Female & 2 & Ataxia & Pineal region & Negative & Negative \\
2 & Female & 3.5 & Ataxia, tremor & Pineal region & Negative & Not analyzed \\
3 & Male & 3.5 & Parinaud syndrome vomiting & Pineal region & Positive & Positive \\
4 & Male & 8 & Parinaud syndrome headache & Pineal region & Negative & Negative \\
5 & Female & 10 & Headache, vomiting & Pineal region & Negative & Negative \\
6 & Male & 14 & Headache & Pineal region & Negative & Negative \\
\hline
\end{tabular}

Table II. Modality of treatment and outcome of patients.

\begin{tabular}{lllllll}
\hline $\begin{array}{l}\text { Patient } \\
\text { No (\#) }\end{array}$ & Biopsy & Resection & Chemotherapy & Radiotherapy & $\begin{array}{l}\text { Survival from } \\
\text { diagnosis (months) }\end{array}$ & Results \\
\hline 1 & Yes & No & Yes & Yes $^{*}$ & 12 & Exitus \\
2 & Yes & No & Yes & Yes & 42 & Exitus \\
3 & Yes & No & Yes & Yes & 24 & Exitus \\
4 & No & Subtotal resection & Yes & Yes & 228 & Exitus \\
5 & No & Subtotal resection & Yes & Yes & 126 & Alive \\
6 & No & Subtotal resection & Yes & Yes & 90 & Alive \\
\hline
\end{tabular}

*: received radiotherapy due to progressive disease, died without completing radiotherapy. 
cancer 9.5 years after treatment for PB. She underwent total thyroidectomy and received radioactive iodine ablation therapy. The patient developed seizures 11 years after treatment. Repeated MRI showed there were hyperintense lesions on the subcortical white matter of the left temporal lobe without contrast enhancement. Later, she developed premature ovarian failure. At the time of this report, the patient is 24 years old and continues receiving anticonvulsants, and hormone replacement for thyroid hormone and ovarian hormones. She has good cognitive function and graduated from university.

A fourteen year old male (Table I, pt\#6), received postoperative CSRT followed by intensive chemotherapy consisting of ifosfamide (1.8 $\mathrm{g} / \mathrm{m} 2 / \mathrm{d} \times 5$ days, etoposide $100 \mathrm{mg} / \mathrm{m} 2 / \mathrm{d} \times 5$ days, and carboplatin $560 \mathrm{mg} / \mathrm{m} 2 /$ day) for eight courses. The tumor responded, but a contrast enhancing residual remained visible by MRI. It could not be resected and did not progress later. The patient is alive, with good cognitive function. Remaining health concerns for him are low testosterone and obesity. He graduated from university and lives independently.

In the first two patients (Table I, pt \#1-\#2) the tumor progressed under treatment, both of their family declined further treatment and the patients passed away.

The tumor of the third patient (Table I, pt \#3) progressed one month after the end of the first line treatment. He received further treatment with a second series of radiotherapy (RT) to the temporal lobe and 12 courses of temozolomide $\left(150 \mathrm{mg} / \mathrm{m}^{2} /\right.$ day X 5 days, every 28 days) chemotherapy. The tumor progressed again and treatment was switched to CCNU (100mg/ $\mathrm{m}^{2} /$ day, every six weeks), nimotuzumab (150 $\mathrm{mg} / \mathrm{m}^{2} /$ dose once a week for 12 weeks and then every other week thereafter), vinorelbine $\left(25 \mathrm{mg} / \mathrm{m}^{2} /\right.$ day on the same day) and intrathecal methotrexate (12 $\mathrm{mg}$ once every week for 3 times). The MRI revealed no response to these protocols, and the treatment was switched again to irinotecan $\left(50 \mathrm{mg} / \mathrm{m}^{2} /\right.$ day $X 5$ days) and temozolamid $\left(100 \mathrm{mg} / \mathrm{m}^{2} /\right.$ day $\times 5$ days $)$ every 3 weeks. The patient died two years after diagnosis due to progressive disease.

A later recurrence was observed in a patient who had subtotal resection at the age of 8 years (Table I, pt \#4). In this patient the residual tumor appeared stable at first, but then progressed after five years. At this time, he was treated with $\mathrm{RT}$ to pineal region and 8 courses of vincristine $\left(1.5 \mathrm{mg} / \mathrm{m}^{2}\right)$, cyclophosphamide $\left(1 \mathrm{gr} / \mathrm{m}^{2} /\right.$ day $)$, procarbazine $\left(50 \mathrm{mg} / \mathrm{m}^{2}\right)$ and CCNU $(100 \mathrm{mg} /$ $\mathrm{m}^{2}$ ). After 1 year, new tumor appeared as an intradural mass in the sacral region (S2). The family refused a biopsy. He was treated again with only local RT to sacral region. The patient lived for 19 years after the first diagnosis of the PB. He had cognitive and endocrinological problems. He died due to a traumatic fall in his house.

None of the patients had a family history of malignancy, none had ophtalmologic evidence of retinoblastoma.

In our study, the median survival time was 5.5 (range:1-19) years. Only 2 patients are alive and are long term survivors.

\section{Discussion}

The pineal region is compromised of the pineal gland, posterior third ventricle, tela choroidea and velum interpositum. The primary pineal tumors are pineoblastoma (PB) and pineocytoma..$^{5}$ Pineoblastomas are rare supratentorial tumors, comprising less than $1 \%$ of childhood brain tumors. Pineoblastomas commonly affect children and young adults, and in our study the median age at presentation was 5.75 years (range: $2-14$ ). ${ }^{6}$ They mainly occur with a short history of clinical symptoms. ${ }^{7,8}$ Signs and symptoms may be nonspecific. Pineoblastomas usually cause third ventricle compression and hydrocephalus leading to vomiting, headaches and somnolence. ${ }^{7-10}$ In our center 6 patients with PB were diagnosed among 516 pediatric brain tumors (1.16 \%) between 1990-2012 and the most common symptoms were headache, Parinaud's syndrome and ataxia. 
Pineoblastomas are embryonal brain tumors similar to medulloblastomas at the histological level, however, at the molecular level there is little similarity. Histologically, these tumors exhibit a classic small round blue cell tumor appearance and Homer Wright and FlexnerWintersteiner rosettes may also be seen occasionally like medulloblastomas. Positivity for the master regulator of retinal photoreceptor differentiation, $C R X$, is positive in $100 \%$ of pineal parenchymal tumors but it is noticed rarely in medulloblastomas. ${ }^{1}$ Similar treatment strategies with high risk medulloblastomas have been suggested for PB. ${ }^{11}$ Additionally, PBs -like medulloblastomas- have a tendency to metastasize to the subarachnoid space. All patients should have an additional metastatic evaluation with MRI of spinal axis and CSF cytology. In our study, 1 of 6 patients had spinal axis seeding metastasis with imaging and CSF positivity.

Germ-line RB-1 mutations predispose to pineoblastoma, in addition de Kock et al. ${ }^{12}$ have reported that DICER1 is an important susceptibility gene for $\mathrm{PB}$ and demonstrated $\mathrm{PB}$ to be a manifestation of a germ-line DICER1 mutation. Additionally, mutually exclusive alterations in other microRNA-processing pathway genes as DROSHA, and DGCR8 were common in PB..$^{13}$ Liu et al. ${ }^{14}$ designed a study of moleculer characteristics of $\mathrm{PB}$ and made five groups as PB-miRNA1, PB-miRNA2, PBMYC/FOXR2, PB-RB1, PPTID. Specification of pineal tumor molecular grouping in CNS tumor classification is suggested to be correlated with clinical characteristics and outcome. None of our patients had an ophtalmic manifestation of retinoblastoma and any of the mutations were not investigated in our cases.

Surgery, radiotherapy and chemotherapy are essential for treatment. Surgery as a cornerstone of the treatment offers rapid symptom relief and is reported to be important for long-term survival. ${ }^{15}$ Although gross total resection (GTR) is generally recommended, this is not possible in most cases. ${ }^{16-20}$ In a recent retrospective analysis of pediatric and adult PB study, totally 64 patients were included and 42 were children. Twenty-six $(61.9 \%)$ of the pediatric patients had GTR, and 16 (38.1\%) had subtotal resection, however, there was no significant association between the extent of resection and overall survival. ${ }^{21}$ In our series, the patients who are still alive had subtotal resection, and all of those that had no resection at all died. Radiation therapy and systemic chemotherapy are also as essential as surgery in this rare aggressive tumor. ${ }^{19}$ All of our patients received CSRT, followed by systemic chemotherapy. Craniospinal irradiation followed by local boost to the tumor bed should be standard..$^{22}$ On the other hand, maximal surgical resection followed by five cycles of intensive chemotherapy and consolidation with myeloablative chemotherapy and autologous hematopoietic cell rescue (HDCx/AuHCR) and/or CSRT was evaluated in the Head Start I, II, and III study. ${ }^{23}$ They found that CSRT and HDCx/AuHCR were statistically associated with improved survival.

Biswas et al. $^{24}$ reported a case series where comprehensive CSRT was used in 15 of 17 patients $(88 \%)$, one patient who received whole brain and ventricular radiation had local and leptomeningeal relapse and died of progressive disease. In a series of 25 patients, progression free survival rates were reported as $47.1 \%$. 12,5 $\%$ and $0 \%$ for those who received CSRT, whole brain RT and focal RT, respectively. ${ }^{23}$ In our series, all patients had CSRT except the one, who was less than 3 years old. A recent study from Germany evaluated the treatment of infants with tumors of the central nervous system (1 patient with PB) with Proton Beam Therapy (PBT) and concluded that PBT is feasible for very young children with central nervous system tumors in the short term. ${ }^{25}$ None of our patients received PBT, it is not available in our country yet.

According to the data from the Surveillance, Epidemiology and End Results (SEER) between 1973-200726, the most important factors were age and degree of spread of tumor in 95 adult patients with $\mathrm{PB}$; younger patients with local disease had the best prognosis. Parikh et al. ${ }^{20}$, in 41 pediatric pineoblastoma cases, have reported 
that, similar to other primitive neuroectodermal tumors, the most significant predictors of survival are age and metastatic disease status on presentation. In the SIOP/UKCCSG PNET 3 study, relatively good survival for nonmetastatic pineal PNETs was reported, and there was no evidence that pre-radiation chemotherapy improved outlook. ${ }^{27}$ Although pineoblastomas were classified as primitive neuroectodermal tumors in previous studies, it is classified under embryonal malignancy group in the recent WHO CNS classification. ${ }^{28}$

The analysis of 135 children with pinealoblastoma in the European Society for Paediatric Oncology (SIOP-E) and US Head Start pooled data showed that in children younger than 4 years of age at diagnosis, conventional chemotherapy without RT was not sufficient to induce sustained remissions in PB. ${ }^{29}$ Friedrich et al. ${ }^{30}$ reported a prospective study about CNSPNET/PB. In this study, from January 2001 to January 2005, 17 eligible children aged $<4$ years diagnosed as CNS-PNET/PB were prospectively treated in the trial HIT-2000. In nonmetastatic disease $(n=11)$ HIT-SKK systemic multiagent chemotherapy followed by CSRT were given. Patients with metastatic disease (M1-M3, n=6) received shorter induction chemotherapy with carboplatin and etoposide, followed by tandem high-dose chemotherapy (HDCT) for those, who had good response to induction therapy. During induction and HDCT, patients received intraventricular methotrexate. Craniospinal RT was given to all patients with poor response to induction or with residual disease. The authors found that short and more intensive induction chemotherapy followed by HDCT was more effective than prolonged moderate induction chemotherapy. ${ }^{30}$ In another prospective metacentric trial, including 11 children and adolescents with $\mathrm{PB}$, all patients had surgery followed by hyperfractionated RT accompanied by weekly intravenous vincristine and then 8 cycles of maintenance chemotherapy (lomustine, cisplatin, and vincristine). ${ }^{31}$ The authors concluded that this treatment strategy was feasible without major acute toxicity and survival rates were comparable to those of a few other recent studies but superior to those of most other series, including the previous trial, HIT 1991. ${ }^{31}$ Gorsi et al. ${ }^{32}$ used nivolumab in pediatric patients with recurrent brain tumors with some transient partial responses. Although in this series, there was only one patient with $\mathrm{PB}$ who had received only one dose of nivolumab, it was suggested to be a promising option in recurrent brain tumors. Additionally, in a retrospective study with limited small sample size with embryonal tumors, HDMTX combined with dose-intensified multiagent chemotherapy was used; it was suggested that in children with high-risk brain tumors who have a poor outcome, High-dose chemotherapy (HDC) and autologous stem-cell transplantation (auto-SCT) could be an option in treatment and promising to improve survival rates. ${ }^{33}$

A retrospective study from China indicated that aggressive surgery as first-line therapy in $\mathrm{PB}$ and younger age was associated with poorer prognosis. ${ }^{34}$

In our series, the patients who lived longer were older than the others. However, they also had resection even it was subtotal, while the others had no resection.

In conclusion, $\mathrm{PB}$ are aggressive tumors necessitating intensive treatment including surgery, CSRT and chemotherapy. High dose chemotherapy is promising in some studies, especially in young patients. Metastasis is a poor prognostic factor. Patients should be treated in institutions with dedicated neurooncology experience and they should be followed up for long term side-effects such as second malignancies, and endocrine deficiencies.

\section{Acknowledgement}

We thank Bilge Bilgic, MD from the Istanbul University, Istanbul Medical Faculty, Department of Pathology for reviewing the pathology results. 


\section{Author contribution}

The authors confirm contribution to the paper as follows: study conception and design: RK, data collection: BK, OG; analysis and interpretation of results: RK, BK, OG. Author; draft manuscript preparation: RK, BK, OG. All authors reviewed the results and approved the final version of the manuscript.

\section{Ethical approval}

Istanbul University Cerrahpasa Medical Faculty Clinical Research Ethical Committee (12.02.2013/ 83045809-3507), İstanbul University Oncology Institute Academic Coordination Council (2013-206).

For this type of study formal consent is not required.

\section{Source of funding}

No funding was received for this research.

\section{Conflict of interests}

Johannes Wolff is employee of AbbVie Pharmaceuticals. The other authors declare that they have no conflicts of interest with regard to this research.

\section{REFERENCES}

1. Meredith DM. Advances in diagnostic immunohistochemistry for primary tumors of the central nervous system. Adv Anat Pathol 2020; 27: 206-219. https://doi.org/10.1097/ PAP.0000000000000225

2. Kleihues P, Cavenee WK (eds). Pathology and Genetics of Tumours of the nervous system. World Health Organisation Classification of Tumours Vol 2. Lyon: International Agency for Research on Cancer (IARC) Press, 2000.

3. Kleihues P, Louis DN, Scheithauer BW, et al. The WHO classification of tumors of the nervous system. J Neuropathol Exp Neurol 2002; 61: 215-225. https:// doi.org/10.1093/jnen/61.3.215
4. Tate M, Sughrue ME, Rutkowski MJ, et al. The long-term postsurgical prognosis of patients with pineoblastoma. Cancer 2012; 118: 173-179. https:// doi.org/10.1002/cncr.26300

5. Alexiou GA, Varela M, Prodromou N. Management of pineal region tumors in children. J Solid Tumors 2012; 2: 15-21. https://doi.org/10.5430/jst.v2n2p15

6. Macdonald DR, Cascino TL, Schold SC Jr, Cairncross JG. Response criteria for phase II studies of supratentorial malignant glioma. J Clin Oncol 1990; 8: 1277-1280. https://doi.org/10.1200/ JCO.1990.8.7.1277

7. Hinkes BG, von Hoff K, Deinlein F, et al. Childhood pineoblastoma: experiences from the prospective multicenter trials HIT-SKK87, HIT-SKK92 and HIT-91. J Neurooncol 2007; 81: 217-223. https://doi. org/10.1007/s11060-006-9221-2

8. Li MH, Bouffet E, Hawkins CE, Squire JA, Huang A. Molecular genetics of supratentorial primitive neuroectodermal tumors and pineoblastoma. Neurosurg Focus 2005; 19: E5. https://doi. org/10.3171/foc.2005.19.5.4

9. Jakacki R, Zeltzer PM, Boyett JM, et al. Survival and prognostic factor following radiation and/ or chemotherapy for primitive neuroectodermal tumors of the pineal region in infants and children: a reports of Childrens Cancer Group. J Clin Oncol 1995; 13: 1377-1383. https://doi.org/10.1200/ JCO.1995.13.6.1377

10. Jakacki RI. Pineal and nonpineal supratentorial primitive neuroectodermal tumors. Child Nerv Syst 1999; 15: 586-591. https://doi.org/10.1007/ s003810050547

11. Reddy AT, Janss AJ, Phillips PC, Weiss HL, Packer RJ. Outcome for children with supratentorial primitive neuroectodermal tumors treated with surgery, radiation and chemotherapy. Cancer 2000; 88: 2189-2193. https://doi.org/10.1002/(SICI)10970142(20000501)88:9<2189::AID-CNCR27>3.0.CO;2-G

12. de Kock L, Sabbaghian N, Druker H, et al. Germ-line and somatic DICER1 mutations in pineoblastoma. Acta Neuropathol 2014; 128: 583-595. https://doi. org/10.1007/s00401-014-1318-7

13. Liu AP, Gudenas B, Lin T, et al. Risk-adapted therapy and biological heterogeneity in pineoblastoma: integrated clinico-pathological analysis from the prospective, multi-center SJMB03 and SJYC07 trials. Acta Neuropathol 2020; 139: 259-271. https://doi. org/10.1007/s00401-019-02106-9

14. Liu AP, Li BK, Pfaff E, et al. Clinical and molecular heterogeneity of pineal parenchymal tumors: a consensus study. Acta Neuropathol 2021; 141: 771785. https://doi.org/10.1007/s00401-021-02284-5 
15. Tomita T. Neurosurgical perspectives in pediatric neurooncology. Childs Nerv Syst 1998; 14: 94-96. https://doi.org/10.1007/s003810050185

16. Cohen BH, Zeltzer PM, Boyett JM, et al. Prognostic factors and treatment results for supratentorial primitive neuroectodermal tumors in children using radiation and chemotherapy: a Childrens Cancer Group randomized trial. J Clin Oncol 1995; 13: 16871696. https://doi.org/10.1200/JCO.1995.13.7.1687

17. Dirks PB, Harris L, Hoffman HJ, Humphreys RP, Drake JM, Rutka JT. Supratentorial primitive neuroectodermal tumors in children. J Neurooncol 1996; 29: 75-84. https://doi.org/10.1007/BF00165520

18. Johnston DL, Keene DL, Lafay-Cousin L, et al. Supratentorial primitive neuroectodermal tumors: a Canadian pediatric brain tumor consortium report. J Neurooncol 2007; 86: 101-108. https:/doi. org/10.1007/s11060-007-9440-1

19. McBride SM, Daganzo SM, Banerjee A, et al. Radiation is an important component of multimodality therapy for pediatric non-pineal supratentorial primitive neuroectodermal tumors. Int J Radiat Oncol Biol Phys 2008; 72: 1319-1323. https://doi.org/10.1016/j.ijrobp.2008.03.033

20. Parikh KA, Venable GT, Orr BA, et al. PineoblastomaThe Experience at St. Jude Children's Research Hospital. Neurosurgery 2017; 81: 120-128. https:// doi.org/10.1093/neuros/nyx005

21. Huo XL, Wang B, Zhang GJ, et al. Adverse factors of treatment response and overall survival in pediatric and adult patients with pineoblastoma. Cancer Manag Res 2020; 12: 7343-7351. https://doi. org/10.2147/CMAR.S258476

22. Paulino AC, Cha DT, Barker JL Jr, Lo S, Manera RB. Patterns of failure in relation to radiotherapy fields in supratentorial primitive neuroectodermal tumor. Int J Radiat Oncol Biol Phys 2004; 58: 1171-1176. https://doi.org/10.1016/j.ijrobp.2003.08.022

23. Abdelbaki MS, Abu-Arja MH, Davidson TB, et al. Pineoblastoma in children less than six years of age: The Head Start I, II, and III experience. Pediatr Blood Cancer 2020; 67: e28252. https://doi.org/10.1002/ pbc. 28252

24. Biswas A, Mallick S, Purkait S, et al. Treatment outcome and patterns of failure in patients of pinealoblastoma: review of literature and clinical experience from a regional cancer centre in North India. Childs Nerv Syst 2015; 31: 1291-1304. https:// doi.org/10.1007/s00381-015-2751-1

25. Jazmati D, Steinmeier T, Khalil DA, et al. Feasibility of proton beam therapy for infants with brain tumours: experiences from the Prospective KiProReg Registry Study. Clin Oncol (R Coll Radiol) 2021; 33: e295-e304. https://doi.org/10.1016/j.clon.2021.03.006
26. Selvanathan SK, Hammouche S, Smethurstv W, Salminen HJ, Jenkinson MD. Outcome and prognostic features in adult pineoblastomas: analysis of cases from the SEER database. Acta Neurochir (Wien) 2012; 154: 863-869. https://doi. org/10.1007/s00701-012-1330-4

27. Pizer BL, Weston CL, Robinson KJ, et al. Analysis of patients with supratentorial primitive neuroectodermal tumours entered into the SIOP/UKCCSG PNET 3 study. Eur J Cancer 2006; 42: 1120-1128. https://doi.org/10.1016/j.ejca.2006.01.039

28. Louis DN, Ohgaki H, Wiestler OD, Cavenee WK. World Health Organization Histological Classifcation of Tumours of the Central Nervous System. France: International Agency for Research on Cancer, 2016.

29. Mynarek M, Pizer B, Dufour C, et al. Evaluation of age-dependent treatment strategies for children and young adults with pineoblastoma: analysis of pooled European Society for Paediatric Oncology (SIOP-E) and US Head Start data. Neuro Oncol 2017; 19: 576-585. https://doi.org/10.1093/neuonc/now234

30. Friedrich $\mathrm{C}$, von Bueren $\mathrm{AO}$, von Hoff $\mathrm{K}$, et al. Treatment of young children with CNS-primitive neuroectodemal tumors/pineoblastomas in the prospective multicenter trial HIT 2000 using different chemotherapy regimes and radiotherapy. Neuro Oncol 2013; 15: 224-234. https://doi.org/10.1093/ neuonc/nos292

31. Gerber NU, von Hoff K, Resch A, et al. Treatment of children with central nervous system primitive neuroectodermal tumors/pinealoblastomas in the prospective multicentric trial HIT 2000 using hyperfractionated radiation therapy followed by maintenance chemotherapy. Int J Radiat Oncol Biol Phys 2014; 89: 863-871. https://doi.org/10.1016/j. ijrobp.2014.04.017

32. Gorsi HS, Malicki DM, Barsan V, et al. Nivolumab in the treatment of recurrent or refractory pediatric brain tumors: a single institutional experience. J Pediatr Hematol Oncol 2019; 41: e235-e241. https:// doi.org/10.1097/MPH.0000000000001339

33. Choi JY, Kang HJ, Hong KT, et al. Tandem high-dose chemotherapy with topotecan-thiotepa-carboplatin and melphalan-etoposide-carboplatin regimens for pediatric high-risk brain tumors. Int J Clin Oncol 2019; 24: 1515-1525. https://doi.org/10.1007/s10147019-01517-8

34. Tian Y, Liu R, Qin J, et al. Retrospective analysis of the clinical characteristics, therapeutic aspects, and prognosis factors of 18 cases of childhood pineoblastoma. World Neurosurg 2018; 116: e162-e168. https://doi.org/10.1016/j. wneu.2018.04.135 